\title{
Cavernous Haemangioma of Uterine Cervix with Pregnancy: A Rare Cause of Antepartum Haemorrhage
}

\author{
Reena Pal ${ }^{1}$, Navajyoti Bora ${ }^{2}$ \\ ${ }^{1}$ Assistant Professor, Department of Obstetrics and Gynaecology, VCSGGMS\&RI,Srinagar Uttarakhand, India \\ ${ }^{2}$ Associate Professor, Department of Obstetrics and Gynaecology, VCSGGMS\&RI,Srinagar Uttarakhand,India
}

\begin{abstract}
Cavernous haemangioma of uterine cervix is very rare benign vascular tumor. Less than 50 cases have been reported till date, amongst them only few cases are associated with pregnancy.Although it is rare but may cause gynaecological and obstetrical complications. Cavernous haemangioma of cervix mainly managed by surgical excision.A multiparous lady at 37weeks pregnancy presented with complaints of something coming out through introitus and bleeding per vaginum following trauma.On examination a mass of $8 \times 4 \times 4 \mathrm{~cm}$ in size, reddish blue in color arising from anterior lip of cervix having laceration on its surface which was bleeding. Caesarian section has been done in view of excessive bleeding per vaginum followed by removal of cervical mass done vaginaly. Histopathological report shows cavernous haemangioma of cervix. Antepartum hemorrhage is very unusual presentation of cervical haemangioma, never reported in literature till now. Although cavernous haemangioma of the uterine cervix in pregnancy is very rare, it should be kept in mind as a differential diagnosis by clinicians as it may cause severe fetomaternal complications.
\end{abstract}

Keywords: Cavernous haemangioma, uterine cervix, pregnancy, antepartum haemorrhage caesarian section

\section{Introduction}

Cavernous haemangioma of uterine cervix is extremely rare, benign vascular lesion, only few sporadic cases have been reported in literature till now[1].Majority of cavernous haemangiomas are asymptomatic diagnosed incidently Its site is primarily visceral like liver, spleen, pancreas, gestrointestinal tract and skin[2].Presenting symptoms are menometrorrhagia, postcoital bleeding, postmenopausal bleeding, sensation of some thing coming out through introitus[3].Association of cavernous haemangioma with pregnancy is very rare.Obstetrical complications are premature rupture of membrane, intrauterine death of fetus, postpartum haemorrhage and disseminated intravascular coagulation[4-7].

In this article we describe a cavernous haemangioma in 30-years old multiparous patient who presented at 37 weeks pregnancy with history of trauma and bleeding per vaginum. Emergency caesarian section has been done followed by cervical vascular tumor removed through vaginal route. This case is reported in view of to emphasis the awareness on existence of cavernous haemangioma of uterine cervix during pregnancy presenting as antepartum haemorrhage that may leads to life threatening bleeding before or at time of delivery may require hysterectomy.

\section{Case Report}

A 30 years old multiparous patient at 37 weeks pregnancy presented in emergency with complaints of something coming out through her introitus and having profuse bleeding per vaginum following trauma. On examination patient was found to be pale and hypotensive,on local examination a large well defined, smooth surfaced mass of $8 \times 4 \times 4 \mathrm{~cm}$ arising from anterior lip of cervix and bulging out through introitus, its color was reddish blue and having a laceration of $3 \mathrm{~cm}$ on its surface through which bleeding was occuring. Os was one finger dilated,bishops score was less than 4.Ultrasonography showed 37 weeks live intrauterine fetus, placenta was posterior upper segment.Emergency caesarian section has been done because of excessive bleeding per vaginum after that mass removed vaginaly. Histopathological finding shows multiple dilated vessels lined by regular endothelial cells, without any atypical mitoses suggestive of cavernous haemangioma.[fig1,2] 


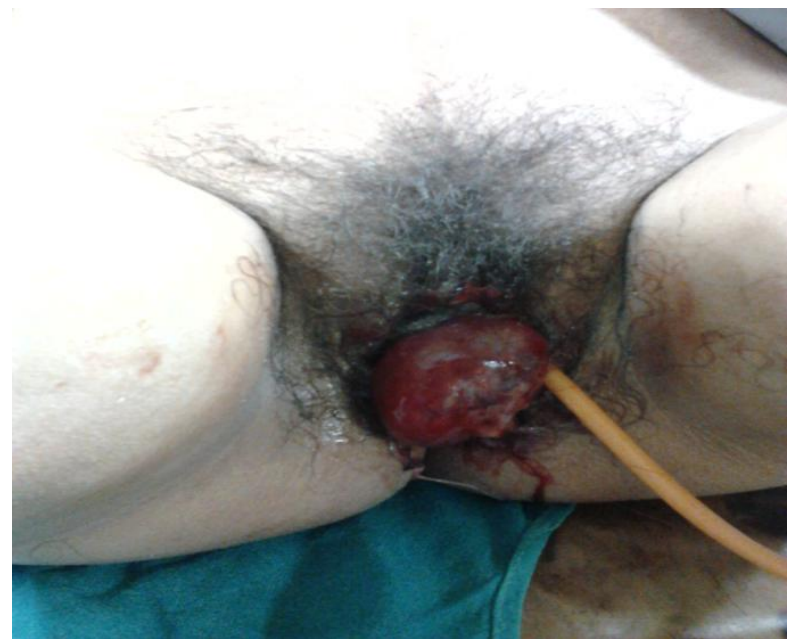

\section{Figure1:A large reddish purple mass coming through vagina}

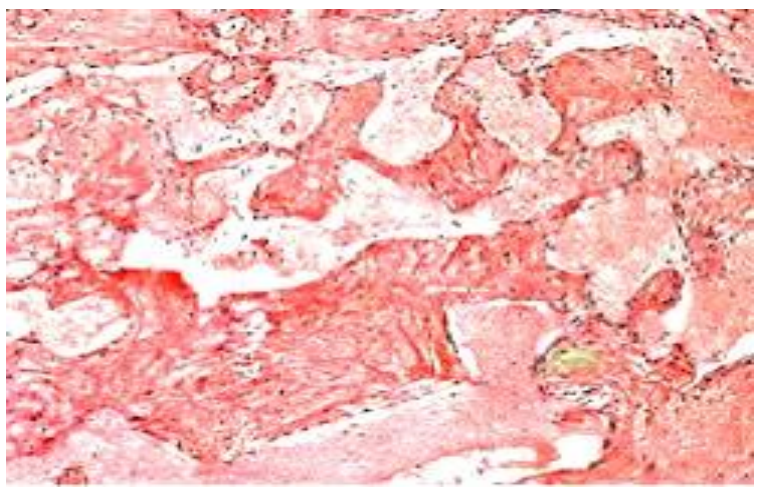

Figure2:Large cavities lined by endothelium and filled with blood

\section{Discussion}

Haemangiomas are benign vascular tumors arising from abnormal accumulation or growth of blood vessels in the internal organs and in the skin..Haemangiomas are classified into capillary,cavernous, arteriovenous or mixed type. Amongst them cavernous haemangioma is less common than other types[8].Cavernous haemangioma usualy present in internal organs and skin but its presence in uterine cervix is very rare site particularly when associated with pregnancy.Fewer than 50 cases has been reported in literature[9].After reviewing the literature we found only 7 cases of cavernous haemengioma of uterine cervix associated with pregnancy besides this case, have been reported[Table1].

Table 1.Various cases of cervical haemangioma of uterus with pregnancy reported in literature

\begin{tabular}{|c|c|l|}
\hline Jackson [10] & 1993 & $\begin{array}{l}\text { Cervical haemangioma is diagnosed in an asymptomatic multiparous woman or during pregnancy, } \\
\text { expectant management is warranted. }\end{array}$ \\
\hline Petry[11] & 1994 & $\begin{array}{l}\text { 31-year old multiparous woman in the 34 + 1 gestational week, who presented herself with a fast } \\
\text { growing cervical haemangioma, indicates that this benign tumor may cause obstetrical complications. }\end{array}$ \\
\hline Riggs [12] & 2003 & $\begin{array}{l}\text { Patient presented intractable bleeding after Medical termination of pregnancy. Required hysterectomy on } \\
\text { Histopathology-cavernous haemangioma. }\end{array}$ \\
\hline Tanaka [13] & 2007 & $\begin{array}{l}\text { The Patient has BRBNS, haemangioma of the uterine cervix appeared during pregnancy. Caesarean } \\
\text { section was performed without complications, One month after delivery, cervical haemangiomas were } \\
\text { found to have decreased in size. }\end{array}$ \\
\hline El Khateb [14] & 2011 & $\begin{array}{l}\text { 25-year old multiparous patient in the 33 - 34 gestational week for premature labor with membranes } \\
\text { rupture. A 3 cm } \times 6 \text { cm soft regular purplish red mass is found in the uterine cervix. Caesarean has been } \\
\text { made for tumor previa interference. The tumor excision has been made through the vagina after } \\
\text { caesarean. }\end{array}$ \\
\hline Mahapatra[15] & 2012 & $\begin{array}{l}\text { A 27-year-old nullipara, at 34 weeks gestation, complained of a sensation of "something coming out of } \\
\text { her introituss. The mass was found to be large, } 8 \text { cm in diameter, and arising from the uterine cervix. } \\
\text { The mass was surgically resected and was sent for histopathological study. Grossly, it was a well } \\
\text { circumscribed,greyish-brown mass, measuring } 6 \mathrm{x} 7 \mathrm{x} 8 \text { cm.iag From the biopsy, the diagnosis that was } \\
\text { made was cervical cavernous haemangioma. The patient later delivered a child by Caesarean section. }\end{array}$ \\
\hline
\end{tabular}

Cavernous haemangioma is either consequences of trauma or congenital malformation. Hereditary factors may play important role in pathogenesis of some familial form of this vascular tumor [16].Development of 
haemangioma may associated with pregnancy and oral contraceptive pills use thereby indicating harmonal role[13].According to Bonetti et al 2009 estrogen plays important role in development of hemangioma,by presence of estrogen receptors in endothelial cells of haemangioma as they detected immunoreactive for CD31,CD34 and factor VIII[17].

Cavernous haemangioma of uterine cervix occurs from nine to 70 years of age but most of these vascular lesions occur during the second and third decades of life and parity does not seem to play a significant role. Majority of them are asymtomatic and diagnosed incidentally[2]. Only 35\% of reported cases were associated with vaginal bleeding (postcoital bleeding,menometrorrhagia). Changes due to harmonal influences during pregnancy may lead to obstetrical complications like premature rupture of membrane,premature labor,fetal death in utero,postpartum haemorrhage and disseminated intravascular coagulation[12].

Most of patient treated with surgical excision,other conservative therapies are cauterization,tracheolectomy,suture ligation, photo coagulation, laser ablation and LEEP $[2,15,18]$. These conservative methods are to preserve fertility in young patients,but intractable bleeding per vaginum may require hysterectomy[4].According to Powel et al hysterectomy to be the primary mode of treatment in $38 \%$ of cases until1991,but during the last decade, hysterectomy has been limited to cases in which conservative management has failed. Surgical intervention, laser, ablation,or cesarean section is reserved for haemangiomas that present major problems[10,12,15,19].But according to S.Elkhateb et al. 2011cavernous haemangioma of uterine cervix with pregnancy may cause severe obstetrical complications so caesarian section is recommended although, delivery by natural ways is possible[14].

\section{Conclusion}

The cavernous haemangioma of uterine cervix is extremely rare particularly when associated with pregnancy.This vascular tumor may cause severe obstetrical complications leading to life threatening conditions.So clinician should be wiser to include cavernous haemangioma of uterine cervix in the differential diagnosis of cervical lesions particularly during pregnancy.Caesarian section and excision of cavernous hemangioma of uterine cervix is recommended in case of acute haemmorrage,large cervical mass causing birth canal obstruction and conservative management can be done in asymptomatic or small cavernous hemangioma.

\section{References}

[1] Gupta R, Singh S, Nigam S and Khurana N., Benign vascular tumors of the female genital tract,International Journal of Gynecology Cancer, 16, 2006, 1195-1200

[2] Kondi-Pafiti A.,Kairi-Vassilatou E, Spanidou-Carvou ni, H., Kontogianni, K., Dimopoulou K. and Goula K., Vascular tumors of the female genital tract: A clinicopathological study of nine cases, European Jour-nal of Gynaecological Oncology, 24,2003, 48-50

[3] Gusdon JP, Haemangioma of the cervix four new cases and a review, American Journal of Obstetrics -Gynecology, 91,1965 204209

Ahern JK and Allen NH, Cervical hemangioma: A case report and review of the literature, Journal of Reproductive Medicine, 21,1978, 228-231

[5] Virk R.K., Zhong J and Lu D, Diffuse cavernous haemangioma of the uterus in a pregnant woman: Report of a rare case and review of literature, Archives of Gynecology and Obstetrics, 279,2008, 603-605.

[6] Talerman A, Hemangioma of the ovary and the cervix, Obstetrics and Gynecology, 30,1967, 108-113.

[7] Cherkis R.C and Kamath C.P, Hemangioma of the uterine cervix and pregnancy: A case report, Journal of Reproductive Medicine, 33,1988,393-395.

[8] Murphey MD, Fairbairn KJ, Parman LM, Kirkman GB, Parsa MB and Smith WS, Musculoskeletal angiomatous lesions , radiologicpathologic correlation, Radio Graphics 15,1995,893-917.

[9] Ozyer S, Uzunlar O, Gocmen M, Bal S, Srvan,L and Mollamahmutoğlu, L, Cavernous hemangioma of the cervix: A rare cause of vaginal bleeding, Journal of Lower Genital Tract Disease, 10,2006, 107-108.

[10] Jackson J, Natural history of a cervical cavernous hemangioma through two pregnancies, 6, Journal of the American Board of Family Practice, 6,1993, 283-287.

Petry K.U, Bernhards J and Jagla K., Cavernous hemangioma of the uterine cervix in pregnancy,Geburtshilfe Frauenheilkd, 54,1994, 62-64.

[12] Riggs J, Bertoni M, Schiavello, H Weinstein A and Kazimir M,Cavernous hemangioma of the cervix with intractable bleeding: A case report, Journal of Reproductive Medicine, 48,2003, 741-74.

[13] Tanaka N, Tsuda M, Samura O, Miyoshi H, Hara T. and Kudo Y, Blue rubber bleb nevus syndrome: Report of a patient with haemangiomas of the vaginal portion of the cervix appearing during pregnancy, Journal of Obstetrics and Gynaecology Research, $33,2007,546-548$.

[14] Samar Elkhateb, Mostafa Azzouzi Idrissi, Kamilia Laabadi, Leila Chbani,Cavernous hemangioma of the cervix and pregnancy:a case report, Open Journal of Obstetrics and Gynecology.1,2011, 221-224 .

[15] Mahapatra S, Das BP, Kar A,A cavernous haemangioma of the uterine cervix during pregnancy, South Afr J Gynaecol Oncol 4(2),2012,63-65.

[16] Batsakis JG,Tumour of the head \& Neck - clinical and pathological considerations. (Baltimore, Williams \& Wilkins, 1978, 1-75.

[17] Reggiani Bonetti, L, Boselli F, Lupi M, Bettelli S, Schirosi L, Bigiani N, Sartori G and Rivasi F, Expression of estrogen receptor in haemangioma of the uterine cervix: Reports of three cases and review of the literature, Archives of Gynecology and Obstetrics, 280, $2009,469-472$

[18] Wang Y.C., Chen C.H., Su H.Y., Li H.S. and Liu J.Y., Huge spindle cell hemangioma of the cervix mimicking a pelvic tumor, Gynecologic and Obstetric Investigation, 60,2005, 98-101.

[19] Powell JL, Stephen JZ and Heather ZS,Hemangioma of the cervix managed with Nd: YAGlaser,ObstetGynecol.78(5),1991,962964. 